\title{
AVALIAÇÃO DA VIABILIDAdE CELULAR E PRODUÇÃo DE POLI(3-HIDROXIBUTIRATO) DE Cupriavidus necator APÓS LIOFILIZAÇÃO UTILIZANDO LEITE DESNATADO COMO CRIOPROTETOR
}

\author{
F. M. MARTINHAGO ${ }^{1}$; W. F. STEFFEN ${ }^{1}$; T. R. GUIMARÃES ${ }^{1}$; C. B. ALVES ${ }^{1}$; W. \\ SCHMIDELL1; G. M. F. de ARAGÃO ${ }^{1}$ \\ ${ }^{1}$ Universidade Federal de Santa Catarina, Departamento de Engenharia Química e Engenharia de \\ Alimentos \\ E-mail para contato: glaucia@enq.ufsc.br
}

\begin{abstract}
RESUMO - A preservação de micro-organismos por diferentes metodologias de secagem tem sido utilizada há décadas. Essas metodologias garantem o armazenamento de culturas por longos períodos de tempo, mantendo suas características fisiológicas. A liofilização é o método preferido para transporte e armazenamento de vastas coleções de cultura de micro-organismos. Este trabalho relata o crescimento e produção de $\mathrm{P}(3 \mathrm{HB})$ por $C$. necator após a bactéria ser submetida à liofilização, utilizando leite desnatado como protetor. A cepa foi cultivada em meio mineral, incubada a $150 \mathrm{rpm} / 35^{\circ} \mathrm{C}$ por $42 \mathrm{~h}$, em seguida, $1 \mathrm{~mL}$ do caldo foi misturado a $1 \mathrm{~mL}$ de leite, acondicionado em tubos de vidro e liofilizados. A viabilidade celular foi determinada com plaqueamento e contagem (expressa em UFC/mL) antes e após $(0,14,21$ e 80 dias) o processo de liofilização. Para efeito comparativo do crescimento de $C$. necator e produção de $\mathrm{P}(3 \mathrm{HB})$ após a liofilização, dois cultivos em frascos foram realizados a partir de uma cepa liofilizada (120 dias após o processo de liofilização) e outra armazenada em glicerol a $-80^{\circ} \mathrm{C}$ (considerado o armazenamento "controle"), apresentando $\mu_{\text {máx }}$ de $0,16 \mathrm{~h}^{-1}$ e $0,15 \mathrm{~h}^{-1}$, respectivamente. Observou-se um decréscimo na contagem total da cepa liofilizada em função do tempo de armazenamento de 5,2×10 ${ }^{8} \mathrm{UFC} / \mathrm{mL}$ logo após o processo de liofilização (sem armazenamento), para $2,4 \times 10^{6}$ após 80 dias. Porém este decréscimo na viabilidade celular não influenciou no crescimento de $C$. necator e a bactéria se mostrou capaz de sintetizar o polímero.
\end{abstract}

\section{INTRODUÇÃO}

Com a crescente preocupação ambiental relacionada às altas quantidades de lixo produzido e considerando-se que grande parte deste lixo é composto por polímeros de difícil degradação, derivados do petróleo, buscam-se alternativas para substituir estes polímeros em sua vasta gama de aplicações (Lee, et al.1996).

O poli(3-hidroxibutirato) $(\mathrm{P}(3 \mathrm{HB})$ ) é um material de reserva energética intracelular, 


\section{9 a 22 de outubro de 2014 \\ Florianópolis/SC}

acumulado por muitos microrganismos sob condições de estresse nutricional, quando há uma fonte de carbono disponível e outro nutriente, como o nitrogênio, o fósforo ou o oxigênio, em concentração limitante. $\mathrm{O} \mathrm{P}(3 \mathrm{HB})$ possui propriedades físicas semelhantes às do polipropileno e pode ser facilmente biodegradado tanto sob condições aeróbias como anaeróbias (Arun et al., 2006).

Dentre os microrganismos que são capazes de sintetizar o $\mathrm{P}(3 \mathrm{HB})$, a bactéria Cupriavidus necator é uma das que apresenta condições mais favoráveis à produção industrial, devido à sua capacidade de acumular até $80 \%$ de seu peso seco em biopolímero e a de assimilar diferentes fontes de carbono (Squio e Aragão, 2004).

Em processos biotecnológicos, é de grande interesse que o organismo seja preservado por um longo período de tempo através de um método que não permita, ou que minimize, a ocorrência de mutações que possam vir a influenciar as características da cultura original (Cameotra, 2007). A preservação de microrganismos por diferentes metodologias é amplamente utilizada, sendo uma destas, a liofilização. A liofilização é uma técnica que associa os métodos de congelamento e desidratação sob condições de vácuo, onde a água e outros solventes do produto congelado são removidos pelo processo de sublimação. (Miyamoto-Shinohara et. al, 2008). Outra metodologia bem difundida de preservação é o congelamento a $-80^{\circ} \mathrm{C}$ com adição de glicerol, que consiste na manutenção de uma variedade de tipos celulares sob baixas temperaturas, tendo como principal objetivo a redução de danos aos materiais biológicos, incluindo células animais e vegetais, bactérias, fungos, vírus e tecidos, durante o processo de congelamento e estocagem a frio (Wolfe e Bryant, 2001).

Agentes protetores podem ser adicionados tanto durante o crescimento do microrganismo quanto momentos antes da liofilização. O tipo de protetor empregado varia de acordo com as características do microrganismo (Hubálek, 2003). Dentre os agentes crioprotetores mais utilizados estão o leite desnatado, a glicose, a trealose, o inositol, entre outros (Tymczyszyn, et al. 2011). Estudos mostram que o leite desnatado é muito empregado por ser capaz de prevenir a lesão celular através da estabilização dos constituintes da membrana celular, criar uma estrutura de poro nos produtos liofilizados, o que torna a reidratação mais fácil e ainda conter proteínas que promovem um revestimento protetor para as células (Abadias et al., 2001).

Frente ao exposto, este trabalho teve como objetivo estudar a preservação da bactéria $C$. necator utilizando o método de liofilização e avaliar sua viabilidade celular e a produção de $\mathrm{P}(3 \mathrm{HB})$ após o processo, utilizando leite desnatado como agente crioprotetor.

\section{MATERIAL E MÉTODOS}

\subsection{Processo de Liofilização da Biomassa e Avaliação da Viabilidade Celular Após o Processo de Liofilização}

Microrganismo e condições de cultivo: O microrganismo utilizado neste trabalho foi a bactéria Cupriavidus necator DSM 545 que estava armazenada em glicerol a $-80{ }^{\circ} \mathrm{C}$ até o momento da inoculação. 


\section{9 a 22 de outubro de 2014 \\ Florianópolis/SC}

As células foram inoculadas em $150 \mathrm{~mL}$ de caldo nutriente (Nutrient Broth - NB), que contém peptona de carne $(5,0 \mathrm{~g} / \mathrm{L})$ e extrato de carne $(3,0 \mathrm{~g} / \mathrm{L})$. A cultura foi incubada em agitador orbital, a $35^{\circ} \mathrm{C}$ e rotação de $150 \mathrm{rpm}$. Após 24 horas, $15 \mathrm{~mL}$ de inóculo foram transferidos para uma segunda pré-cultura, de caldo nutriente com a mesma composição e volume da primeira, e incubado sob as mesmas condições durante 18 horas. Em seguida, uma alíquota de $40 \mathrm{~mL}$ foi transferida para o meio mineral, sem limitação de nitrogênio, conforme descrito por Ienczak et al. (2011).

Amostras foram retiradas, a partir do meio mineral, em intervalos de duas horas, para o acompanhamento do crescimento celular por espectrometria a $600 \mathrm{~nm}$. Os dados foram utilizados para determinar a curva de crescimento do microrganismo estudado ( $\ln$ Abs X tempo), definindo a velocidade específica máxima de crescimento, para posterior realização da liofilização das células colhidas em fase exponencial de crescimento.

Liofilização: Para a liofilização da cultura celular, adicionou-se $1 \mathrm{~mL}$ do caldo cultivado em meio mineral a $1 \mathrm{~mL}$ de leite desnatado em tubos de vidro de $8 \times 120 \mathrm{~mm}$, com espessura de parede de $1 \mathrm{~mm}$. Os tubos foram mantidos a $-20^{\circ} \mathrm{C}$ por 6 horas, e posteriormente transferidos para câmara de secagem, a $-50^{\circ} \mathrm{C}$ e pressão de $6 \mathrm{mmHg}$, por 24 horas. O liofilizador utilizado foi da marca Liobras, modelo L101. Após este processo, os tubos foram selados. Todo este processo foi realizado de maneira estéril, evitando-se assim a contaminação da cultura.

Viabilidade Celular: A fim de se verificar a viabilidade celular do microrganismo estudado ao longo do tempo após o processo de liofilização, plaqueamentos foram realizados em $0,14,21$ e 80 dias após este processo.

\subsection{Avaliação da Capacidade de Crescimento e Produção de $\mathbf{P}(3 \mathrm{HB})$ por $C$. necator Após o Processo de Liofilização}

O cultivo para estudar a produção de $\mathrm{P}(3 \mathrm{HB})$ foi realizado a partir de duas pré-culturas em NB e uma terceira em meio mineral, como descritas no item 2.1. O meio de cultivo final também foi realizado em meio mineral, porém com limitação em nitrogênio, com concentrações iniciais de glicose/frutose e nitrogênio de 40 e $1 \mathrm{~g} / \mathrm{L}$, respectivamente.

Dois estudos cinéticos de crescimento, conforme descrito acima, foram realizados: um foi inoculado com a bactéria liofilizada e outro (controle) com a cepa mantida a $-80{ }^{\circ} \mathrm{C}$ em glicerol, para avaliar a influência do processo de liofilização capacidade de crescimento e produção de $\mathrm{P}(3 \mathrm{HB})$ por C. necator.

\subsection{Técnicas Analíticas}

Amostragem: Amostras de $2 \mathrm{~mL}$ foram coletadas a cada $2 \mathrm{~h}$ e acondicionadas em microtubos de plástico e centrifugadas (10956 xg por $3 \mathrm{~min}$ ). Os sobrenadantes e os precipitados foram congelados separadamente para posteriores análises de substrato residual e acúmulo de polímero.

Determinação da concentração da biomassa: O acompanhamento do crescimento da biomassa 
foi realizado por espectrofotometria a $600 \mathrm{~nm}$ e por meio de análise gravimétrica, em que o precipitado obtido após a centrifugação de $2 \mathrm{~mL}$ da amostra foi submetido à secagem em estufa a $100{ }^{\circ} \mathrm{C}$ por $24 \mathrm{~h}$. Após este tempo, as amostras foram colocadas em dessecador por 20 minutos e pesadas. A amostragem foi realizada em triplicata.

Determinação da concentração de açúcares redutores totais: A determinação de açúcares redutores totais (ART) foi realizada pelo método do ácido 3-5 dinitrosalicílico (DNS) (Miller, 1959).

Determinação da concentração de nitrogênio: O nitrogênio foi determinado utilizando-se o kit Uréia ES (Gold Analisa) que determina uréia pelo método enzimático-colorimétrico.

Determinação da concentração de $\mathrm{P}(3 \mathrm{HB})$ : A concentração de $\mathrm{P}(3 \mathrm{HB})$ foi determinada por cromatografia gasosa, conforme o método de metanólise baseado Brandl et al. (1988).

\subsection{Tratamento dos Dados}

Considerando-se que o acúmulo de $\mathrm{P}(3 \mathrm{HB})$ é intracelular, define-se: Xt (biomassa total) = biomassa contendo $\mathrm{P}(3 \mathrm{HB})$ e $\mathrm{Xr}$ (biomassa residual $)=\mathrm{Xt}-\mathrm{P}(3 \mathrm{HB})$.

Velocidade específica de crescimento da biomassa: A partir dos perfis de concentração da biomassa residual, foi possível determinar as velocidades instantâneas de crescimento microbiano (dXr/dt). Dividindo-se estas velocidades pela concentração celular residual no instante t, a velocidade específica de crescimento celular $\left(\mu_{\mathrm{Xr}}\right)$ foi obtida e está representada pela Equação 1.

$$
\frac{1}{\mathrm{X}} \frac{\mathrm{dXr}}{\mathrm{dt}}=\mu_{\mathrm{Xr}}
$$

Integrando a Equação 1, obtém-se a Equação 2.

$$
\operatorname{Ln}(\mathrm{Xr})_{\mathrm{x}_{0}}^{\mathrm{x}}=\mu_{\mathrm{Xr}}(\mathrm{t})_{\mathrm{t}_{0}}^{\mathrm{t}}
$$

Como a concentração celular possui relação linear com a absorbância do meio, pode-se simplificar a Equação 2, obtendo-se a Equação 3, onde $\mu_{\mathrm{Xr}}$ passa a ser o coeficiente angular de uma reta. Abs representa a absorbância em um tempo t ao longo do cultivo, e $\mathrm{Abs}_{0}$ a absorbância no

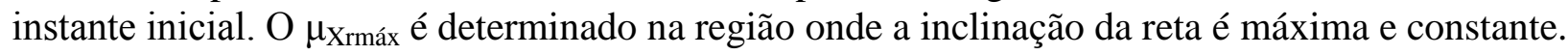

$$
\operatorname{Ln}(X r)=\mu_{\mathrm{Xr}}(\mathrm{t})
$$

A determinação da velocidade específica máxima de crescimento $\left(\mu_{\text {Xrmáx }}\right)$ foi realizada para posterior comparação entre a atividade biológica da cepa antes e depois da liofilização.

\section{RESULTADOS E DISCUSSÃO}

Na tabela 1 estão apresentados os resultados do acompanhamento da viabilidade celular do 
microrganismo ao longo do período de estocagem. Foi possível perceber um rápido decaimento na viabilidade celular logo após o processo de liofilização. Decorridos 80 dias de armazenamento, a viabilidade reduziu para 0,17\%. Bozoglu et al. (1987) sugerem que sobrevivência de $0,1 \%$ da população original é um "número suficiente" de sobreviventes para posterior reativação das mesmas.

Tabela 1 - Unidades formadoras de colônias por mL e viabilidade celular de $C$. necator após o processo de liofilização ao longo do período de armazenamento de 0, 14, 21 e 80 dias.

\begin{tabular}{cccccc}
\hline $\begin{array}{c}\text { Tempo } \\
\text { (dias) }\end{array}$ & $\begin{array}{c}\text { Anterior à } \\
\text { liofilizaçãa }\end{array}$ & 0 & 14 & 21 & 80 \\
\hline UFC/mL & $2,86 \times 10^{10}$ & $5,55 \times 10^{9}$ & $8,51 \times 10^{8}$ & $8,05 \times 10^{8}$ & $4,87 \times 10^{7}$ \\
$\begin{array}{c}\text { Viabilidade } \\
(\%)\end{array}$ & 100 & 19,37 & 2,97 & 2,81 & 0,17 \\
\hline
\end{tabular}

No cultivo realizado em frascos agitados, buscou-se estudar o comportamento cinético da cepa de $C$. necator liofilizada, em termos de crescimento celular, consumo de substrato e produção de $\mathrm{P}(3 \mathrm{HB})$, após o processo de liofilização. Para fins de comparação, um cultivo controle foi realizado nas mesmas condições descritas anteriormente, porém uma cepa armazenada em glicerol a $-80{ }^{\circ} \mathrm{C}$ foi utilizada como inóculo.

A curva de crescimento gerada a partir do $\operatorname{Ln}(\mathrm{Xr})$ ao longo do tempo, é apresentada na Figura 1, para o cultivo controle e para o cultivo realizado a partir de células liofilizadas, e foi utilizada para definir o $\mu_{\text {Xrmáx. }}$

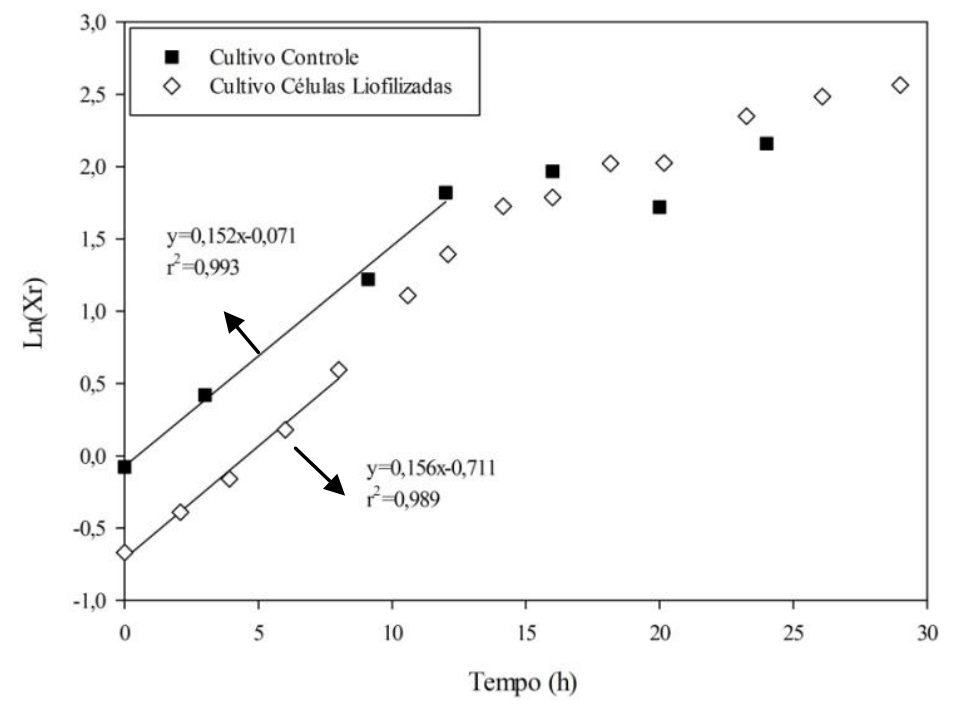

Figura 1 - Representação logarítmica da biomassa residual de $C$. necator armazenada em glicerol a $-80{ }^{\circ} \mathrm{C}(\boldsymbol{\square})$ e liofilizada $(\diamond)$ ao longo do tempo de cultivo em glicose e frutose, para obtenção da velocidade específica máxima de crescimento. 
Como é possível observar na Figura 1 , os valores de $\mu_{\text {Xrmáx }}$ obtidos foram de 0,15 e $0,16 \mathrm{~h}^{-1}$ para a célula armazenada em glicerol a $-80^{\circ} \mathrm{C}$ e para a célula liofilizada, respectivamente. Esta comparação mostra que para ambos os cultivos o $\mu_{\text {Xrmáx }}$ foi semelhante, comprovando assim a efetividade do processo, pois conservou as propriedades da cepa.

Estudos realizados por Zayed e Roos (2004) mostraram que a preservação de Lactobacillus salivarius utilizando leite desnatado como crioprotetor atingiu viabilidade celular de aproximadamente $22 \%$. Neste trabalho $19,37 \%$ das células se mantiveram viáveis, o que está de acordo com a literatura.

Nas Figuras 2 e 3 são apresentados os dados de concentração de biomassa total (Xt), P(3HB), biomassa residual glicose/frutose e nitrogênio residuais ao longo do tempo, para o cultivo controle e para o cultivo a partir de células liofilizadas, respectivamente.
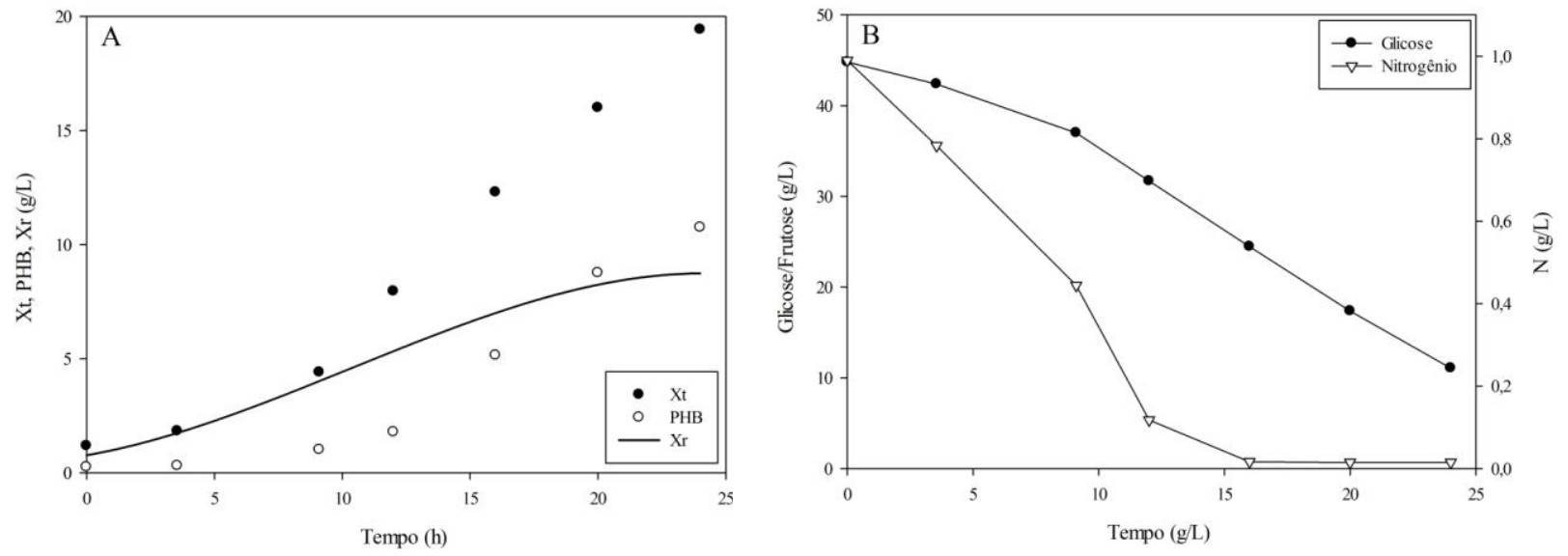

Figura 2 - Concentração de biomassa total (Xt), de P(3HB) e de biomassa residual (Xr) (A); glicose/frutose e nitrogênio residuais $(\mathrm{B})$ ao longo do tempo para $C$. necator armazenada em glicerol a $-80^{\circ} \mathrm{C}$.

Apesar do valor de $\mu_{\text {Xrmáx }}$ obtido para cinética com biomassa liofilizada ser bem próximo ao valor encontrado para o cultivo controle, quando se compara os resultados de produção do polímero é possível perceber que o acúmulo de $\mathrm{P}(3 \mathrm{HB})$ foi inferior para o cultivo da cultura liofilizada, quando comparado ao cultivo controle, sendo de 30 e 55,4 \%, respectivamente. É possível verificar também, que diferentemente do cultivo com $C$. necator armazenada em glicerol, onde ocorreu a exaustão de $\mathrm{N}$ em torno de $15 \mathrm{~h}$, no cultivo a partir de células liofilizadas, esta exaustão ocorreu apenas após 25 horas de cultivo, esta diferença no consumo deste substrato pode justificar a diferença entre os percentuais finais de acúmulo de biopolímero. 

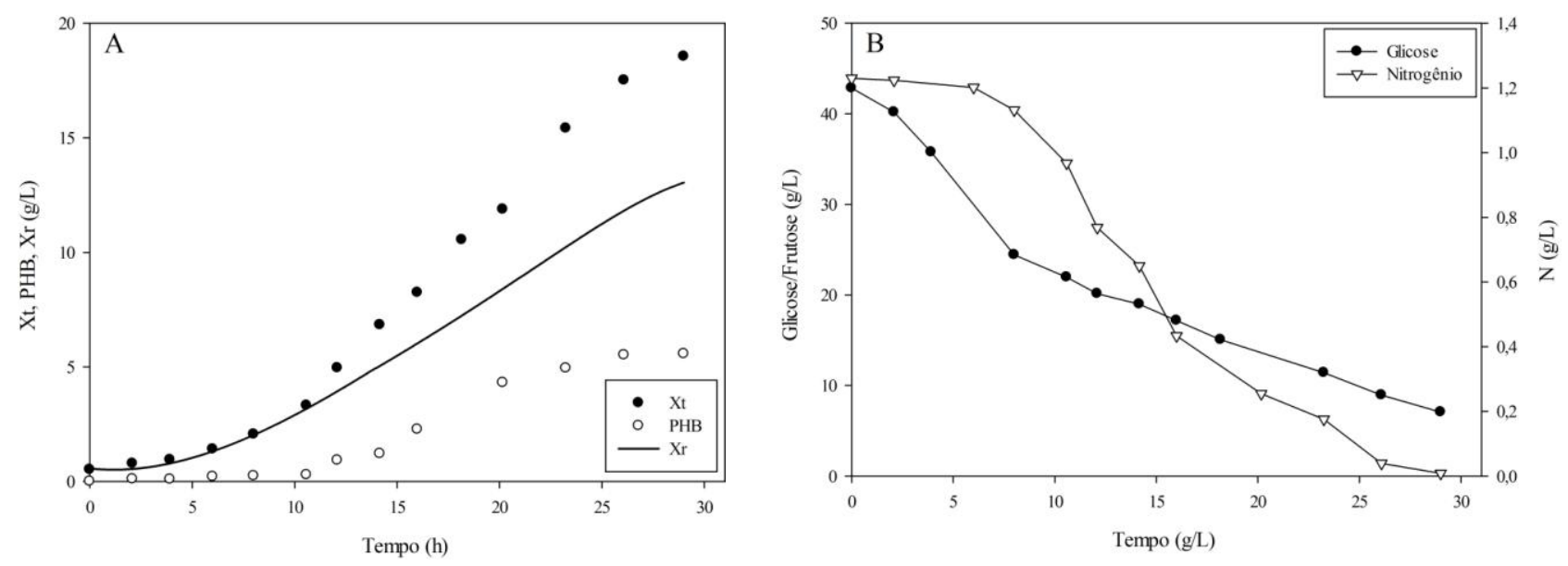

Figura 3 - Concentração de biomassa total (Xt), de P(3HB) e biomassa residual (Xr) (A); glicose/frutose e nitrogênio residuais (B) ao longo do tempo para C. necator liofilizada.

Ao avaliar as Figuras 2 e 3 (B), percebem-se que ao final dos cultivos a concentração da fonte de carbono estava próxima a $10 \mathrm{~g} / \mathrm{L}$, sendo que esta concentração já pode ser considerada insuficiente para a produção de $\mathrm{P}(3 \mathrm{HB})$ a partir de $C$. necator. No cultivo controle, no momento da exaustão em $\mathrm{N}$, a concentração de carbono disponível era superior a $25 \mathrm{~g} / \mathrm{L}$ possibilitando assim um maior acúmulo de $\mathrm{P}(3 \mathrm{HB})$, devido à maior disponibilidade de glicose/frutose no meio durante a fase de produção.

\section{CONCLUSÃO}

Os resultados de viabilidade celular mostraram que, apesar de sofrer um decréscimo ao longo do tempo, a cepa liofilizada permaneceu suficientemente viável após 80 dias de armazenamento.

Pelo valor de $\mu_{\text {Xrmáx }}$ obtido em ambos os cultivos, percebe-se que o processo de liofilização proposto foi eficiente na manutenção da cepa, pois apresentou crescimento semelhante ao da cepa armazenada em glicerol a $-80^{\circ} \mathrm{C}$.

Apesar da manutenção da viabilidade celular e do $\mu_{\text {Xrmáx }}$ obtido na cinética de crescimento a partir de células liofilizadas ser similar ao do cultivo controle, o consumo de nitrogênio pela cepa liofilizada apresentou comportamento diferente do controle, porém mesmo assim, foi possível observar o acúmulo de polímero de $30 \%$ nesta cultura.

\section{REFERÊNCIAS}

ABADIAS, M.; BENABARRE, A.; TEIXIDÓ, N.; USALL, J.; VIÑAS, I. Effect of freeze-drying and protectants on viability of the biocontrol yeast Candida sake. International Journal of Food Microbiology, v. 65, p. 173-182, 2001.

ARUN, A.; MURRUGAPPAN, R.; RAVINDRAN, A.D.D.; VEERAMANIKANDAN, V.; BALAJI, S.Utilization of various industrial wastes for the production of poly-beta-hydroxy butyrate 
(PHB) by Alcaligenes eutrophus. African Journal of Biotechnology., v. 5, p. 1524-1527, 2006.

BOZOGLU, T.F.; OZILGEN, M.; BAKIR, U. Survival kinetics of lactic acid starter cultures during and after freeze drying. Enzyme Microbiology Technology, v. 9, p. 531-537, 1987.

BRANDL, H. GROSS, R. A.; LENZ, R. W.; FULLER, C. Pseudomonas oleovorans as a source of poly( $\beta$-hydroxyalkanoates) for potential applications as biodegradable polyesters. Applied Environmental Microbiology, v. 54, p. 1977-1982. 1988.

CAMEOTRA, S. S. Preservation of microorganisms as deposits for patent application, Biochemical and Biophysical Research Communications, v. 353, p. 849-850, 2007.

HUBÁLEK, Z. Protectants used in the cryopreservation of microorganisms. Cryobiology, New York, v. 46, p. 205-229, 2003.

IENCZAK, J. L.; QUINES, L. K.; MELO, A. A. de; BRANDELLERO, M.; MENDES, C. R.;SCMIDELL, W.; ARAGÃO, G. M. F. High cell density strategy foir poly(3hydroxybutyrate) production by Cupriavidus necator. Brazilian Journal of Chemical Engineering, Vol. 28, No. 04, pp. 585 - 596, October - December, 2011.

LEE, S. Y.; KIM, G. J.; CHOI, D. K.; YEON, B. K.; PARK, Y. H. Improvement of hydroxyvalerate fraction in poly( $\beta$-hydroxybutyrate-co- $\beta$-hydroxyvalerate) by a mutant strain of Alcaligenes eutrophus. Journal of Fermentation and Bioengineering, v. 81, p. 255-258, 1996.

MILLER, G. L. Use of dinitrosalicylic acid reagent for determination of reducing sugars. Analytical Chemistry, v. 31, p. 426-428. 1959.

MIYAMOTO-SHINOHARA Y, SUKENOBE J, IMAIZUMI T, NAKAHARA T. Survival of freezedried bacteria. The Journal of general and applied microbiology, Tokyo, v. 54, n.1, p. 9-24, feb./ 2008.

SQUIO, C. R.; ARAGÃO, G. M. F. Estratégias de cultivo para produção dos plásticos biodegradáveis poli(3-Hidroxibutirato) e poli(3-hidroxibutirato-co-3-hidroxivalerato) por bactérias, Química Nova, v. 7, 2004.

TYMCZYSZYN, E. E.; GERBINO, E.; ILLANES, A.; GÓMES-ZAVAGLIA, A. Galactooligosaccharides as protective molecules in the preservation of Lactobacillus delbrueckii subsp. bulgaricus. Cryobiology v. 62, p. 123-129, 2011.

WOLFE, J.; BRYANT, G. Cellular cryobiology: thermodynamic and mechanical effects. International Journal of Refrigeration, Surrey, v. 24, p. 438-450, 2001.

ZAYED, G., ROOS Y. H. Influence of trehalose and moisture content on survival of lactobacillus salivarius subjected to freeze-drying and storage. Process Biochemistry, 36, 1081 - 1086, 2004 